\title{
La educación para los medios en la oferta educativa profesional en el norte de México
}

\author{
Dr. Jorge Cortés Montalvo \\ Facultad de Filosofía y Letras \\ Universidad Autónoma de Chihuahua, México
}

\section{RESUMEN}

Se analizan los diferentes tipos de interacción entre los medios de comunicación y los programas educativos de nivel profesional. Se reporta el resultado de una exploración en la oferta de programas de licenciatura en siete instituciones de educación superior en la capital del estado de Chihuahua, México, en cuanto al contenido de elementos de educación para los medios.

\section{ABSTRACT}

Diferent kind of interaction between mass media and educational programs are review. The exploration in several programs of height education in seven university institutions in Chihuahua, México, about media literacy are reported.

Palabras claves: Medios de comunicación/ Educación superior/ Audiencias/ Educación para los medios.

Key words: Mass Media/ Height education/ Target/Media literacy.

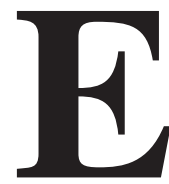

1 trabajo que en esta oportunidad se pone a consideración del lector tiene que ver en su acepción más amplia con el ámbito de la comunicación educativa. Los planteamientos en torno a la reconversión educativa que se lleva a cabo en casi todos los países de occidente y particularmente en América Latina, donde se pone de relieve la calidad, pertinencia y cobertura, en todos los niveles, pero específicamente en el rango de la educación superior, atendiendo a los enfoques globalizadores de todos los sectores y, como en el caso de México, por recomendaciones de la $\mathrm{OCDE}^{1}$, y aun al margen de los intereses que defiende y de la postura ideológica de dicha organización, precisa de una reconceptualización de formas, contenidos y modelos que tornen eficaz y

1 Examen de la política educativa en México, Informe de los examinadores de la OCDE, México, 1994. 
eficiente el esfuerzo y la inversión que supone la formación de hombres y mujeres, conforme al tipo de ciudadano, culto, preparado y sobre todo habilitado, que exigen los retos de una sociedad global, cada vez más abierta en los comienzos de este siglo $\mathrm{XXI}^{2}$.

Cuando hablamos de comunicación educativa hacemos referencia por lo menos a dos situaciones: los procesos de comunicación en las aulas y en los ambientes educativos, que se refiere en particular a las condiciones de enseñanza y aprendizaje comprendidas en los diseños curriculares, programas y contenidos académicos, incluida la habilidad didáctica del profesorado y la educación para la comunicación o más específicamente, la educación para los medios de comunicación.

En este planteamiento, podemos examinar las posibles implicaciones de dos preguntas básicas: a) ¿qué hacen los medios por o para la educación? y b) ¿qué hace la educación por o para los medios?

Así, identificamos cuatro vertientes:

\section{- A.1. La utilización de medios como recurso didáctico en las aulas:}

En tiempos recientes se ha dado un gran impulso en México al equipamiento de los centros educativos de recursos audiovisuales y tecnológicos de última generación, como apoyo al trabajo docente. La planta académica cuenta ya con una gran cantidad de dispositivos para la impartición de sus asignaturas, concomitantemente, recibe de manera continua capacitación para la utilización de pizarras y rotafolios electrónicos, retroproyectores, cañones de proyección conectados a cpu's, grabadoras y reproductoras de audio y video. Asimismo los ordenadores y toda clase de software son recursos de gran valor que ya no pueden faltar en el salón de clase. Tradicionalmente se ha considerado que mientras más versátil y variada sea la utilización de imágenes, sonidos y ejemplos sensibles a la percepción será mayor la capacidad de aprendizaje de los estudiantes. Los medios técnicos y tecnológicos utilizados en el aula no solamente vuelven más creativas las tareas y exposiciones sino que, en muchos casos, complementan y se sobreponen a los viejos recursos didácticos llegando incluso a sustituir algunas funciones del profesor y, desde luego, a apoyar de manera definitiva las exposiciones de los estudiantes.

Los apoyos tecnológicos que abundan cada vez más, se complementan con la utilización de los contenidos informativos que viajan por ellos: así, es ya más que usual que los estudiantes recurran al periódico, a la radio y a los spots

2 Organización de las Naciones Unidas para la Educación, la Ciencia y la Cultura (UNESCO), Conferencia Mundial Sobre la Educación Superior, La educación superior en el siglo XXI: Visión y Acción. París 59 Oct. 1998. 
televisivos como soporte de sus exposiciones y como referente de situaciones del acontecer local, nacional o mundial en un momento dado, que deba ser ligado al contenido de las asignaturas, como, por ejemplo, las materias sobre economía, sobre actualización legislativa, sobre fenómenos del acontecer político de los tiempos que corren, etc. ${ }^{3}$

Cosa semejante ocurre con muchos profesores y profesoras que actualizan su información acudiendo a las noticias presentadas por la prensa y por los medios electrónicos y, en consecuencia, los temas pertinentes y de más reciente cuño que ejemplifican el sentido de sus cátedras.

La radio y la televisión educativa han sido inestimables en llevar formación y cultura a grupos que habitan en zonas alejadas de los centros urbanos del país, entre las montañas o en los más alejados pueblos indígenas o campesinos, donde las escuelas son galerones de madera con cajas, cuando no piedras como pupitres, atendidas por un maestro rural mal capacitado y peor pagado -regiones que aunque parezca impensable ya entrado el siglo XXI, abundan todavía en este país, y que llegan como mucho al sexto año de instrucción primaria.

Otro recurso mediático, más humilde pero no por ello menos importante, es la historieta, que ha sido utilizada también, con mediano éxito, como fórmula de llevar educación a grandes sectores de las poblaciones urbanas ${ }^{4}$.

Indudablemente, la red de Internet es hoy por hoy un recurso punta de tecnología en comunicaciones que ha cobrado rápidamente carta de ciudadanía entre profesores y alumnos en la educación universitaria.

Los gruesos volúmenes de las enciclopedias temáticas han quedado como alimento de polillas en los libreros y estantes de las bibliotecas en virtud de que las búsquedas e investigaciones se realizan cada vez más acudiendo a la navegación en internet, donde materialmente se encuentra cualquier cosa que uno busque, incluso muchas que uno no busca, pero que se enlazan sin remedio al teclear un descriptor.

El tan socorrido "chat" es también una fuente de consulta que prácticamente ha abatido las distancias en la comunicación entre individuos y grupos, aunque es usado en gran medida, todavía, como recurso lúdico de conversación.

Rápidamente, sin embargo, se está poniendo de moda la oferta de programas educativos a través de la red, encontramos en consecuencia, cursos de todo tipo, incluidas maestrías y doctorados en modalidades abiertas y a distancia, y aun en los cursos escolarizados, que están todavía lejos de desaparecer, los docentes se han 'actualizado' poniendo foros de discusión, tareas, y lecturas en la red y también consultas por medio del correo electrónico.(MINIAN, 2001)

3 Consultar APARICI, Roberto. (comp.) (1997): Antología, UPN, ILCE.

4 Ver GONZÁLEZ VIDEGARAY, Maricarmen (1998): "La historia como instrumento educativo", en VVAA. Didáctica de los medios de comunicación, SEP, México. 


\section{- A.2. Los medios propiamente como instancia educadora:}

El otro asunto de este apartado es el que considera el papel de los medios como instaladores de patrones de comportamiento y de formas de entender la realidad social, cultural, económica, política y de todo orden, los medios influyen en el pensamiento de las personas, no porque manipulen o conduzcan directamente las formas de pensamiento, sino porque tienen una gran capacidad de seducción y tienen mucho éxito señalando a sus audiencias sobre qué tienen que pensar, aspecto que ha sido ya señalado por Saperas (1987).

Los medios educan, nos presentan modelos de sociedades y culturas prejuzgándolas como mejores o peores, esquemas que explican cosas inexplicables, formas de vida a las que hay que aspirar o de las que hay que huir, estilos y maneras de ser dramáticas o gratificantes, ficciones que parecen realidades y viceversa.

Todos nosotros, hasta los más viejos, formamos parte de una generación que ha sufrido o disfrutado de la exposición prolongada a cualquier tipo de medio, así desde las primeras experiencias preceptúales, las personas identifican los códigos -sin alcanzar a descifrarlos, ya que para ello se requiere un proceso de alfabetización mediática, concepto que abordaremos más adelante- con los cuales establecen contacto y quedan enganchados en la representación mediática.

Javier Esteiniou (2000), resume esta condición cuando afirma que

“ La construcción o destrucción de la realidad masiva cotidiana, es decir, de lo que existe o no existe, de lo que es bueno o es malo, de lo que hay que recordar o hay que olvidar, de lo que es importante o no, de lo que es verdad o es mentira, de lo que son valores o antivalores, de lo que es opinión pública o de lo que no lo es, de lo que es virtuoso o no, de lo que hay que hablar o hay que silenciar, de lo que hay que admirar o rechazar, de lo que es el éxito o el fracaso, etc. Se elabora, cada vez más, especialmente en las grandes ciudades, desde los medios colectivos de difusión. El peso de los canales de información masiva es tan acentuado sobre la conformación mental de la sociedad que podemos decir que la realidad no son los medios de información, pero los medios contribuyen sustancialmente a construir la realidad central que reconoce la mayoría de la población. Los medios no son la política, pero hoy no se puede hacer política sin la acción persuasiva de los sistemas de información colectivos. No son el aparato jurídico, pero hoy los medios se han convertido en los "tribunales electrónicos" que linchan o absuelven a las figuras públicas antes de que el estado recurra a los procesos constitucionales de oficio. No son los partidos políticos, pero producen el mayor caudillismo electrónico que toda la capacidad proselitista directa que realizan las organizaciones políticas. No son la economía, pero ninguna economía contemporánea puede funcionar sin la cultura de consumo que producen los medios de información, vía su práctica publicitaria. No son la memoria del país, pero hoy la agenda del recuerdo social cotidiana se construye progresivamente desde los medios de difusión de masas". 
La proliferación de la gran infraestructura de entretenimiento y sobre todo informativa en el país, ha contribuido a modificar sustancialmente los hábitos culturales de la vida cotidiana de los mexicanos. Al principio del siglo XXI, apunta el mismo autor, "los mexicanos somos los habitantes que más vemos televisión en todo el continente americano, con un promedio diario superior a las cuatro horas. De aquí, que empezando este tercer milenio, la población mexicana se haya transformado de una cultura de lectores a una cultura de televidentes, de lo cual se deriva un peso muy sustantivo de los medios audiovisuales en la formación de sus gustos, actitudes, opiniones, conductas, mentalidades y visiones de la vida"s.

- B.1. La tercera vertiente a que hacemos alusión es la que se refiere a la formación profesional y a la profesionalización de periodistas e informadores:

Las instituciones de educación superior y particularmente las universidades, han apostado a replantear los esquemas educativos, sometiéndolos a un riguroso examen para determinar las transformaciones y adecuaciones que deben ser considerados a fin de actualizar las estructuras curriculares, en el ánimo de formar individuos más acordes con los modelos globales que se instalan irreductiblemente en, por lo menos, los llamados países occidentales del planeta, en el entendido de que las viejas concepciones de formación de profesionales deben ser superadas, e incluso sustituidas por fórmulas emergentes que gradualmente van descontinuando, o al menos reconvirtiendo, las carreras tradicionales ${ }^{6}$.

Hasta hace poco tiempo, el periodismo y el manejo de información en México eran actividades que se ejercían de oficio, había que empezar como aprendiz y gradualmente ir adquiriendo la habilidad observando a los ya fogueados, a fuerza de golpes, ensayos y errores, de fracasos y de escasas y difíciles posibilidades de hacer méritos, se iban formando e instalando las habilidades para llegar a ser reporteros o, en amplio reconocimiento, periodistas. Cosa semejante ocurría con aquellas personas que atendían las bibliotecas, cuya labor era tan simple como aprender a clasificar por autor, título o género, multitud de libros pesados y polvosos, encontrarlos en los estantes para quienes los solicitaban y volver a acomodarlos en su sitio una vez desocupados, eso y mantener las salas de consulta en silencio era la labor de la o del bilbiotecario. No había que ser profesional para ello.

Ahora las cosas han cambiado, no solamente se han abierto carreras emergentes para la formación de periodistas, comunicólogos, diseñadores gráficos,

5 Autor. Op. Cit.

6 Son los propósitos declarados por la Asociación Nacional de Universidades e Instituciones de Educación Superior (ANUIES), de México, como política que deber normar la educación superior hasta el año 2020. 
informólogos, etc., - abundan las carreras de comunicación - sino que las opciones se han extendido a la profesionalización de periodistas e informadores en activo, tal es el modelo que ha seguido la carrera de periodismo de la UACh con generaciones únicas. La tendencia es romper con la idea de que hay un tiempo para estudiar y otro para trabajar, o de que sólo acceden a la formación profesional los jóvenes que salen de la educación media superior o los bachilleres, ahora el diseño de muchos currículos, se orientará a otorgar el reconocimiento y el respaldo institucional de la universidad a distintos oficios que, en consecuencia, se incluirán en el catálogo de nuevas profesiones. Antes de eso y atendiendo a recomendaciones de organismos internacionales como la OCDE o la UNESCO, las universidades tendrán que certificar sus programas y sistemas académicos, y aun estandarizarlos eventualmente, para que los niveles de competencia propuestos, tengan también un reconocimiento global.

El cuarto aspecto, que es el centro temático de este escrito, se refiere a

\section{- B.2. La educación formal e informal de las audiencias:}

Las personas por lo regular se enteran de lo que está pasando en el mundo a través de los medios de comunicación, en virtud de que no pueden tener información de primera mano, sólo en la medida y en los formatos en que los medios dan tratamiento al conjunto de asuntos que se privilegian y que constituyen la agenda temática de los medios. En realidad de lo que la gente se entera, es de lo que dicen los medios de comunicación que ocurre en el mundo, con las limitaciones de cada medio. Por lo tanto, la gente está al tanto de una realidad social en cierto sentido creada por los medios, que, aunque tenga relación y referencia directa con la "realidad real" (valga la redundancia), no es propiamente dicha realidad, sino la realidad producida y adaptada según el formato de cada medio, es decir, la realidad de los medios. La gente cree pues estar enterada de lo que pasa en su localidad, en la región, en el país y en el mundo, pero es un conocimiento falaz o, en el mejor de los casos, sumamente parcial e intencionado, ya que la audiencia por lo general ignora cómo se produce la noticia, las características técnicas de su elaboración, selección y tratamiento, así como buena parte de los códigos y metalenguajes que se utilizan en los medios a través de los cuales se difunde. Los medios tienen pues una gran capacidad para crear "realidades" y presentarlas a sus audiencias como "la realidad", porque los medios no reflejan, como muchos piensan, la realidad, sino que construyen realidades. (BERGER y LUCKMAN, 1979).

Mucho se ha avanzado en considerar la educación para los medios, también denominada educomunicación (KAPLÚN, M. 1997), cada vez más como componente que como complemento de los programas educativos de nivel básico, desde el jardín de párvulos, hasta la educación secundaria llegando incluso al nivel 
preprofesional, en el entendido de que los contenidos mediáticos comprenden un factor formativo que debe ser atendido desde la propia estructura del currículo ${ }^{7}$, no obstante, existen pocas referencias de la experiencia latinoamericana de propuestas de educación para los medios en los programas de educación superior, tal vez en el supuesto de que los estudiantes del ciclo profesional, están suficientemente capacitados para entendérsela con los mensajes que viajan a través de los medios y de las tecnologías de información y comunicación.

Las universidades y las instituciones de educación terminal, egresan año tras año flamantes profesionistas que salen al mundo a incorporarse al mercado de trabajo con los conocimientos y herramientas que han logrado recuperar en sus años estudiantiles. Un mundo y un mercado de trabajo cuyo soporte está estructurado sobre los sistemas, tecnologías y medios de comunicación, y que con mayor frecuencia de la que pensamos, el orgulloso profesional novel ignora qué intereses están detrás de ellos, como son sus procesos de producción de información y cuáles los propósitos, ocultos o manifiestos, de esa máquina de crear opinión. En suma, con título y todo, son analfabetos mediáticos.

El fenómeno del analfabetismo audiovisual, dice Masterman (1993), es una realidad palpable en la sociedad contemporánea. Cada vez más investigaciones y estudios demuestran que el consumo masivo e indiscriminado de los medios no lleva parejo -más bien al contrario- un conocimiento de los códigos del lenguaje audiovisual, provocando situaciones de indefensión ante sus mensajes.

Pero ¿qué es educación para los medios? Según José Martínez de Toda y Terrero (1999) "Educación para los medios es un proceso que busca formar e informar en el sujeto un conjunto de dimensiones educativas que empiezan por la alfabetización mediática; es decir, generar una mentalidad consciente, activa, crítica, social y creativa. Tal educación debe permitirle participar como generador, y no sólo como audiencia pasiva en la cultura popular contemporánea, tal como es presentada en los medios masivos."

El ministerio de educación de Ontrario, Canadá, consigna en su Guía de Recursos de alfabetización audiovisual, la siguiente definición: "la educación para los medios es una contribución para que el estudiante desarrolle un conocimiento y una comprensión crítica de la naturaleza de los medios de información, de las técnicas que utilizan y la incidencia de dichas técnicas en el pensar y el actuar de los individuos, para que de esta manera estén en conocimiento de cómo funcionan los medios, cómo producen significados, cómo se organizan y cómo construyen la realidad" (SHEPHERD, 1997).

7 Ver al efecto el notable y profuso trabajo de Manuel Area Moreira, de la Universidad de La Laguna y de múltiples experiencias reportadas por investigadores de muy variada extracción disciplinaria en instituciones de España y Latinoamérica, entre otros GARCCEA MATILLA (1997); CABERO, J. (1997); APARICI, R. (1997); AGUADED, J.I. (1999), y los trabajos que publica el ILCE y Chasqui entre muchos otros. 
El planteamiento sobre la necesidad de generar una educación para los medios, aparece en Europa, Canadá y los Estados Unidos hacía la segunda mitad del siglo XX, y aunque en México y el resto de Latinoamérica se ha venido trabajando intensamente en la última década en este sentido, los esfuerzos se han orientado fundamentalmente a la educación primaria y secundaria. No se tiene conocimiento de su aplicación sistemática en la educación universitaria o terminal, al menos en México, salvo en programas muy específicos relacionados de manera directa con los medios de comunicación, en carreras como Periodismo y Ciencias de la Comunicación.

En su devenir, ajuste, desarrollo y proceso de profesionalización los medios hacen lo conducente por ampliar y flexibilizar sus formatos, por presentar la información de manera clara, comprensible y desde diversos ángulos. Muchos periodistas se encuentran francamente comprometidos con su profesión y ponen su empeño y su talento para hacer el mejor periodismo posible. Corresponde a la instancia educativa, en todos sus niveles y modelos, crear las condiciones para educar a las audiencias y ponerlas en capacidad de leer más allá de la nota periodística, para ver y escuchar con ojos y oídos críticos la versión radiofónica o televisiva de los noticiarios y para distinguir entre la ficción del entretenimiento y la realidad creada y configurada por los medios. Esto es doblemente válido para los propios estudiantes universitarios y en general en el sistema de educación terminal. Creemos que una competencia fundamental en su repertorio de recursos profesionales, sea cual sea su campo de acción profesional, es precisamente el conocimiento y la comprensión crítica de la información de todo tipo que viaja por los medios, pero también, la habilidad para crear sus propios mensajes, para identificar el sentido y los efectos sociales y culturales de los mensajes mediáticos y mediatizados.

Habría que señalar qué acciones son y cuáles no corresponden a la educación para los medios, nos apoyamos para tal propósito en las acciones descritas por Area Moreira (2002 a):

\begin{tabular}{|l|l|}
\hline QUÉ NO ES EpM & QUÉ ES EpM \\
\hline $\begin{array}{l}\text { Los procesos de comunicación en los } \\
\text { proyectos educativos }\end{array}$ & $\begin{array}{l}\text { Educar para ampliar las capacidades de } \\
\text { análisis activo y crítico de la oferta te- } \\
\text { levisiva, periodística y radiofónica y, } \\
\text { en general, mediática }\end{array}$ \\
\hline $\begin{array}{l}\text { La comunicación interpersonal en los } \\
\text { salones de clase, o la comunicación pro- } \\
\text { fesor-alumno }\end{array}$ & $\begin{array}{l}\text { Actividades encaminadas a convertir a } \\
\text { un oyente pasivo en un receptor crítico } \\
\text { de la radio }\end{array}$ \\
\hline $\begin{array}{l}\text { El uso de aparatos de radio y Televi- } \\
\text { sión o periódicos para apoyar el apren- } \\
\text { dizaje de los contenidos de las materias }\end{array}$ & $\begin{array}{l}\text { Orientar hacia la naturaleza esencial de } \\
\text { los medios como son sus lenguajes y } \\
\text { códigos, sistemas de símbolos, etc. }\end{array}$ \\
\hline
\end{tabular}




\begin{tabular}{|l|l|}
\hline $\begin{array}{l}\text { La teleeducación o educación a distan- } \\
\text { cia así como la utilización de la radio y } \\
\text { la Televisión educativa como auxiliares } \\
\text { didácticos }\end{array}$ & $\begin{array}{l}\text { Integrar los contenidos programáticos } \\
\text { en función de los medios de comunica- } \\
\text { ción, mediante el dominio de los ele- } \\
\text { mentos técnico narrativos y semánticos } \\
\text { específicos de cada medio }\end{array}$ \\
\hline $\begin{array}{l}\text { Los cursos sobre manejo de software o } \\
\text { de navegación en internet, así como los } \\
\text { cursos de informática o sistemas com- } \\
\text { putacionales }\end{array}$ & $\begin{array}{l}\text { Metodologías destinadas a la autofor- } \\
\text { mación en el análisis y evaluación de } \\
\text { mensajes difundidos a través de los } \\
\text { medios }\end{array}$ \\
\hline $\begin{array}{l}\text { La producción de materiales multime- } \\
\text { dia, el uso de materiales impresos o } \\
\text { audiovisuales }\end{array}$ & $\begin{array}{l}\text { Aprender cómo se selecciona la infor- } \\
\text { mación que aparece en los periódicos, } \\
\text { cómo se hacen las emisiones radiofóni- } \\
\text { cas y televisivas para entender los con- } \\
\text { tenidos y tratamientos, sus propósitos } \\
\text { implícitos y explícitos, calidad técnica } \\
\text { y valor en imagen y sonido }\end{array}$ \\
\hline $\begin{array}{l}\text { Las videoconferencias } \\
\text { Entre otros.... }\end{array}$ & $\begin{array}{l}\text { Enseñar al estudiante a crear y generar } \\
\text { sus propios mensajes a través de los } \\
\text { medios }\end{array}$ \\
\hline \begin{tabular}{l} 
Entre otros.... \\
\hline
\end{tabular}
\end{tabular}

Kathleen Tyner (1997) identifica ocho ideas principales que debería comprender la educación para los medios:

1. Todo lo que comunican los medios son construcciones: Los medios no reproducen ni reflejan la realidad, ofrecen construcciones cuidadosamente realizadas que han sido sometidas a numerosas pruebas y decisiones.

2. Los medios de comunicación construyen la realidad: Una parte importante de las observaciones y experiencias en las que basamos nuestra representación de lo que es el mundo y como funciona, nos llega previamente construido por los medios, con actitudes, interpretaciones y conclusiones incorporadas.

3. Las audiencias negocian el contenido de los medios de comunicación: Cada uno de nosotros busca o "negocia" el significado de manera diferente dependiendo de muy diversos factores: necesidades y ansiedades 
personales, placeres y problemas cotidianos, actitudes raciales, regionales o sexuales, medio familiar y cultural.

4. Los medios tienen implicaciones comerciales y económicas: La educación para los medios integra el análisis de aspectos tales como quiénes son los dueños de los medios, a qué grupos pertenecen, cuáles son sus compromisos comerciales y publicitarios y cuáles son los efectos que de esto deriva. La estudiantes universitarios por lo regular ignoran que un número muy pequeño de banqueros, empresarios o políticos adinerados controlan todo lo que vemos, leemos u oímos en los medios.

5. Los medios de comunicación contienen mensajes ideológicos: Todos los productos de los medios son, en cierto modo, publicidad de sí mismos y también de valores y formas de vida; los grandes medios transmiten de manera implícita o explícita valores ideológicos.

6. Los medios tienen implicaciones sociales y políticas: Los medios están íntimamente vinculados al mundo de la política y los cambios sociales. La televisión o los periódicos pueden influir, y lo hacen en la elección de determinado candidato a través de la imagen y el marketing político, también involucrarnos en temas como el SIDA o la lucha antiterrorista.

7. Forma y contenido están íntimamente relacionados: Cada medio tiene su propia gramática y codifica la realidad bajo su propio formato. Así pues, los diferentes medios de comunicación informan del mismo acontecimiento pero crean diferentes impresiones y mensajes.

8. Cada medio tiene su propia estética y fórmula de seducción: Del mismo modo que disfrutamos de la belleza de la música, de la literatura poética o en prosa, debemos ser capaces de apreciar las formas y efectos agradables con que nos atrapan los medios de comunicación.

Ante tales planteamientos y consideraciones, surgió muy clara una pregunta de investigación ¿hasta donde cumplen las instancias educativas universitarias y de educación superior con esta labor de educar para los medios?

$\mathrm{Y}$ en concreto:

¿Tienen los programas académicos de la oferta de carreras universitarias, contenidos que enseñen a los estudiantes los procesos de elaboración noticiosa, los códigos periodísticos y en general mediáticos, las presiones, 
intereses corporativos y clientelares y juegos de poder que están detrás de los medios?

Como toda pregunta conlleva de alguna manera una respuesta, ésta se planteó en forma de

\section{Hipótesis de trabajo:}

'Sólo aquellos programas relacionados con la formación de periodistas, comunicadores o informadores, incluyen contenidos, de manera parcial, con estas características, el resto de los programas para todo tipo de carreras, simplemente los ignora o no los considera pertinentes en su perfil de ingreso o de egreso'.

Un grupo de dieciséis estudiantes, atrapados en las materias de Diseño de investigació; ocho en la licenciatura en Ciencias de la Información y de Comunicación Educativa, en la Maestría en Educación Superior; ocho más de la Universidad Autónoma de Chihuahua, México ${ }^{8}$, a quienes agradezco su empeño y dedicación, accedieron a trabajar en el proyecto durante el primer semestre del 2002, bajo el siguiente esquema metodológico:

\section{Metodología de investigación:}

Consistió en identificar los programas académicos de la oferta de carreras profesionales en diferentes instituciones de la localidad, a través de las páginas web o directamente en cada institución, se seleccionaron por su disponibilidad, de acuerdo a como los estudiantes que participaron fueron auto asignándose según su elección, un total de 52 programas de siete instituciones de educación superior fueron revisados. De las carreras elegidas se anlizaron los programas curriculares y en detalle las materias o asignaturas utilizando como criterio la búsqueda e identificación de elementos afines a la lista que previamente se elaboró, agrupando una serie de conceptos que definen qué es y qué no es educación para los medios,

8 Agradezco la valiosa colaboración de los estudiantes participantes en la investigación:

\begin{tabular}{|l|l|}
\hline $\begin{array}{c}\text { Diseño de investigación en la Lic. } \\
\text { en Ciencias de la Información }\end{array}$ & \multicolumn{1}{|c|}{$\begin{array}{c}\text { Comunicación Educativa en la Maestría } \\
\text { en Educación Superior }\end{array}$} \\
\hline Rocío Muñiz Luna & $\mathrm{M}^{\mathrm{a}}$ Judith Gandarilla M. \\
\hline Mirna Chacón Portillo & Rosana Aguirre Hernández \\
\hline Alba Castro Baeza & Edgar Pacheco G. \\
\hline Farah Estrada Zubiate & Diana García Rivera \\
\hline Anabel Loya Ramos & Claudia Isela Gutiérrez Quezada \\
\hline Adriana Pérez Rodríguez Alonso & Ana Gabriela Salas Solorio \\
\hline Rocío Ledezma Caldera & Julián Fernández Aldana \\
\hline Brianda López y López & Arturo Salvador Caballero Burgos \\
\hline
\end{tabular}


descritos por Area Moreira (2002 a) en correspondencia con el listado antes expuesto y en concordancia con tres entradas de análisis en una matriz:

- Texto: incorpora el análisis de cualesquier formato mediático, así como de los contenidos en la programación radiofónica o televisiva y de la línea editorial o tratamiento noticioso de los diarios, tanto en su carácter teórico como de aplicación operativa, según el tipo de asignatura, disciplina y nivel en que se imparte.

- Audiencia: Se analiza el contenido de las asignaturas del programa de la carrera, buscando en específico si alguna incluye el análisis del tipo de segmento al que van dirigidos los mensajes mediáticos, independientemente de si tienen directa o indirectamente, relación con la disciplina a que pertenece el programa.

- Producción: Se busca identificar actividades curriculares o extracurriculares que habiliten al estudiante en la producción y elaboración de mensajes en cualquier formato y medio.

\begin{tabular}{|l|l|l|l|}
\hline & Políticas Institucionales & Contenidos temáticos & Práctica docente \\
\hline Texto (formato) & & & \\
\hline Audiencias (Target) & & & \\
\hline Producción de información & & & \\
\hline
\end{tabular}

Aquellas asignaturas, seminarios, talleres y actividades académicas que contuvieran algún elemento listado, fue escudriñada con mayor detalle en tres dimensiones académicas identificadas como:

- Políticas institucionales: se trató de advertir si en la misión y la visión de la institución, consignado en el perfil de egreso de la carrera específica a que corresponde o pertenece la asignatura, se encuentra algún elemento descriptivo o explicativo que permita considerar como incluyente la EpM.

- Contenidos temáticos y programáticos de la asignatura: consistió en identificar si en el programa académico de la materia o en alguna parte de sus contenidos temáticos se incluyeron elementos de EpM. 
- Práctica docente: resultó de la exploración, de acuerdo con el reporte directo de estudiantes y profesores, de que, independientemente de que las dos facetas descritas anteriormente incluyeran o no elementos de EpM durante las sesiones académicas, el docente hubiera incluido temas, prácticas o ejercicios orientados hacia algún aspecto de la EpM.

\section{Resultados:}

$>$ Solo una institución de las 7 revisadas, el Instituto Tecnológico de Estudios Superiores de Monterrey (ITESM), incluye componentes de EpM en las tres dimensiones propuestas: Política institucional, Contenidos programáticos y Práctica docente, específicamente en el Tronco Común de las 10 carreras que ofrece y en un grupo de materias de especialidad para carreras relacionadas con la comunicación.

$>$ El resto de las instituciones no incluyen ni contemplan la inclusión de componentes de EpM

$>$ En la mayoría de los casos, autoridades, profesorado y estudiantes ignoran a que se refiere el concepto de Educación para los Medios, aunque consideran que, en todo caso, es una asignatura propia de las Ciencias de la Comunicación.

$>$ En los casos en que aparece aisladamente un componente de EpM en algunas materias de los programas revisados, éste corresponde, en confirmación de la hipótesis planteada, a carreras referidas a la comunicación o sus variantes, no obstante, la orientación del contenido no tiene ese propósito específico, sino que es colateral a los objetivos de la materia. (Ver detalle en la tabla) 


\begin{tabular}{|c|c|c|c|c|c|c|c|}
\hline INSTITUCIÓN & PROGRAMA & P.I. & P.A. & P.D. & № de MATERIAS & CONTENIDOS & DESCRIPCIÓN \\
\hline $\begin{array}{l}\text { Universidad Autónoma de } \\
\text { Chihuahua }\end{array}$ & $\begin{array}{l}\text { Facultad de Ciencias Agrotec- } \\
\text { nológicas } \\
\text { FACIATEC } \\
\text { >Lic. Admon. Agrotecnológica } \\
\text { >Lic. Sist. Inf. Agrícola } \\
\text { >Ing. Prod. y Com. Hortícula } \\
\text { Facultad de ZOOTECNIA } \\
\text { >Ing. Zootecnista } \\
\text { >Ing. en Ecología } \\
\text { Facultad de Contabilidad y Ad- } \\
\text { ministración } \\
\text { >L.S.C.A. } \\
\text { >L.A.E. } \\
\text { >C.P. }\end{array}$ & & & & $\begin{array}{l}\text { Comunicación } \\
\text { Organizacional }\left(4^{\circ}\right)\end{array}$ & $\begin{array}{l}\text { Definición del proceso } \\
\text { Información estadistica } \\
\\
\text { Sistemas de teleproceso } \\
\text { Proceso de comunicación } \\
\text { Campañas promocionales }\end{array}$ & $\begin{array}{l}\text { No vinculada a EPM } \\
\text { Bases de datos } \\
\text { Modelos y niveles de efectividad } \\
\text { en las organizaciones }\end{array}$ \\
\hline $\begin{array}{l}\text { Instituto Tecnológico de Es- } \\
\text { tudios Superiores de Mon- } \\
\text { terrey }\end{array}$ & $\begin{array}{l}\text { >L.A.E. } \\
\text { >L.. Financiera } \\
\text { >L. Derecho } \\
\text { >L. Mercadotecnia } \\
\text { >L. Comercio internacional } \\
\text { >L. Relaciones Internacionales } \\
\text { >l. Ind. y de Sistemas } \\
\text { >l. Mećnico Adm. } \\
\text { > Ing. Mecatrónica } \\
\text { > >ng. Sistemas Electrónicos }\end{array}$ & $x$ & $x$ & $x$ & $\begin{array}{l}\text { TRONCO COMÚN } \\
\text { a)Análisis del discurso } \\
\text { b)Redacción avanzada } \\
\text { c)Análisis de Inf. } \\
\text { d)Comunicación oral FUE- } \\
\text { RA DE T.C. } \\
\text { a)Semiótica aplicada } \\
\text { b)Comunicación intercultu- } \\
\text { ral }\end{array}$ & $\begin{array}{l}\text { Lectura y análisis crítico de infor- } \\
\text { mación, géneros periodísticos, lec- } \\
\text { tura crítica, elaboración de periódi- } \\
\text { co y revista, lenguaje periodístico, } \\
\text { comunicación oral utilizando me- } \\
\text { dios } \\
\text { Importancia de los mass media y } \\
\text { su aplicación }\end{array}$ & $\begin{array}{l}\text { En los primeros tres niveles } \\
\text { como texto y audiencia, en los } \\
\text { últimos tres producción de men- } \\
\text { sajes }\end{array}$ \\
\hline $\begin{array}{l}\text { Universidad Regional del } \\
\text { Norte }\end{array}$ & $\begin{array}{l}\text { >Lic. Contaduría Pública Fis- } \\
\text { cal } \\
>\text { >Lic. C. Comunic. } \\
>\text { >L.A.C. } \\
\text { >L. Admon. Ind. } \\
\text { >L. Comercio Ext. } \\
\text { >Lic. Relaciones Internaciona- } \\
\text { les } \\
>\text { >ngeniería Finan. } \\
>\text { Derecho. } \\
\text { >L. Negocios Internacionales } \\
>\text { >L. Turismo }\end{array}$ & & $\mathrm{x}$ & & $\begin{array}{l}\text { Teoría de la comunicación } \\
\text { Masiva } \\
\text { Análisis de información y } \\
\text { opinión pública }\end{array}$ & $\begin{array}{l}\text { Sólo en la carrera de C. de la co- } \\
\text { municación incorpora tres asigna- } \\
\text { turas con elementos que pueden } \\
\text { corresponder a EpM }\end{array}$ & $\begin{array}{l}\text { Ninguna materia plantea espe- } \\
\text { cíficamente la EPM aunque se } \\
\text { aplique de forma colateral }\end{array}$ \\
\hline $\begin{array}{l}\text { Instituto Tecnológico de } \\
\text { Chihuahua } 1\end{array}$ & 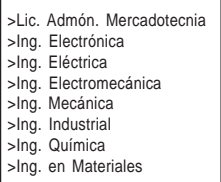 & & & & & & \\
\hline $\begin{array}{l}\text { Universidad Interamericana } \\
\text { del Norte }\end{array}$ & $\begin{array}{l}\text { >Ing. Ind. Sistemas } \\
\text { >Ing. Industrial en Automati- } \\
\text { zación Electrónica y Comuni- } \\
\text { cación } \\
\text { >L. Admón. } \\
\text { >L. Sistemas de computación } \\
\text { Administrativa } \\
\text { >Contador Público } \\
\text { >L. Derecho y Asuntos Inter- } \\
\text { nacionales } \\
\text { >L. Comercio Internacional } \\
\text { >L. Mercadotecnia } \\
\text { >L. Diseño Grático } \\
>\text { >L. C. Comunicación }\end{array}$ & & $x$ & & $\begin{array}{l}\text { Opinión pública } \\
\text { Comunicación masiva }\end{array}$ & $\begin{array}{l}\text { La materia de comunicación masi- } \\
\text { va considera los efectos y el im- } \\
\text { pacto de los massmedia y su utili- } \\
\text { zación en la educación. } \\
\text { Se incluye el análisis de los me- } \\
\text { dios en la formación de la opinión } \\
\text { pública }\end{array}$ & $\begin{array}{l}\text { Sólo la carrera de comunicación } \\
\text { contempla aspectos de EPM }\end{array}$ \\
\hline C.U.P. & $\begin{array}{l}\text { L. en Contabilidad } \\
>L \text {. en Admón. } \\
>L \text {. en Sistemas } \\
>\text { L. en Artes Visuales }\end{array}$ & & $x$ & & $\begin{array}{l}\text { Contenidos, audiencia y } \\
\text { producción }\end{array}$ & $\begin{array}{l}\text { Sólo se aplica a algunas catego- } \\
\text { rías de análisis }\end{array}$ & \\
\hline $\begin{array}{l}\text { ESCUELA NORMAL DEL } \\
\text { EDO. }\end{array}$ & $\begin{array}{l}\text { >L. Educ. preescolar } \\
\text { >L. Educ. primaria }\end{array}$ & & & & & & \\
\hline
\end{tabular}

Resultados del análisis de los programas de 52 carreras profesionales que se ofertan en siete instituciones de educación superior, de tipo universitario y tecnológico, en la ciudad de Chihuahua, México

Elaboración propia a partir de los datos obtenidos en el análisis de los programas disponibles en páginas web, trípticos descriptivos y respuesta a entrevistas semiestructuradas en el periodo comprendido entre febrero y junio del 2002. 


\section{Conclusiones:}

Los medios de comunicación ofrecen una organización del universo, un sistema de signos, valores, normas y conocimientos; para ello utilizan códigos, formatos y formas específicas y altamente sofisticadas de transmisión de información. El contacto frecuente y continuado con los medios, sea con fines de diversión y esparcimiento o bien -y especialmente- con propósitos informativos, son consustanciales a la experiencia académica, ya que de ellos proviene buena parte de los conocimientos y aprendizajes que sobre el mundo y los procesos de todo tipo tienen los estudiantes.

Hoy resulta, por lo menos ingenuo, quedarse en la crítica, la denuncia o la satanización de los medios de comunicación como ideologizadores y enajenantes de las mentes estudiantiles, porque si bien esto es cierto, hay que reconocer que forman parte inevitable de nuestra cultura y nos proporcionan información y entretenimiento de una manera espectacular y fascinante.

No basta llamar la atención sobre los efectos de los medios o asegurarse de su utilización como recurso didáctico en el salón de clase, sino que es necesario determinar una estrategia para paliar el enorme poder de convencimiento y seducción que tienen los medios, cuyos fines e intereses no son del todo claros a quiénes se exponen directamente a la lectura de un periódico o a la capacidad envolvente de los electrónicos. Dicha estrategia, consiste en educar a la población para develar los contenidos encubiertos de los mensajes y ampliar así su capacidad selectiva. Es verdad que dicha educación debe iniciar en el jardín de niños y continuar a lo largo de toda la formación escolar, esta postura, cuyo énfasis está puesto en el receptor, es la que se está desarrollando en diversos países del mundo como Educación para los medios (EPM), y en algunos casos ya forma parte del currículo de los distintos niveles educativos, pero, por tratarse en nuestro contexto de una propuesta que recientemente se está poniendo en práctica, es menester dedicarle particular atención a su implementación en los niveles superiores de formación profesional.

El análisis de los programas académicos, implica la localización de un conjunto de elementos de contenido que conduzcan a asegurar una formación que le permita al futuro profesionista comprender lo que hay detrás de los medios, los recursos expresivos que utilizan, el entramado oculto de las estrategias de producción y sus propósitos y, desde luego, los intereses económicos, políticos y en general culturales que subyacen a las distintas fórmulas mediáticas.

Detectar la carencia de estos elementos formativos en los contenidos de los programas académicos de la oferta en el nivel profesional, puede servir como llamada de atención para incorporar, en futuras revisiones curriculares, factores que permitan una formación integral en este sentido, a los estudiantes que al término de su formación, habrán de contribuir en marcar las pautas de desarrollo para la sociedad del siglo XXI. 


\section{Bibliografía consultada:}

- AGUADED, José I. (s/f): "La Educación para los Medios. Modelos Asociativos en España y Portugal", en caminhos para o encontro educativo, editado por Escola Superior de Educaçao da Universidade do Algarbe (Portugal) y la Universidad de Huelva (España). (pp. 417-426)

- ANUIES (Asociación Nacional de Universidades e Instituciones de Educación Superior)(1999): La Educación Superior en el Siglo XXI: Líneas estratégicas de Desarrollo. México.

- APARICI, R. (1997) (comp.): La educación para los medios de comunicación, UPN, México.

- AREA M. Manuel (2002 a): "La Educación de los Medios de Comunicación y su Integración en el Currículo Escolar", Universidad de la Laguna, http:// www.quadernsdigitals.net/articles/pixel/pixel4/p4educación.html (cons. 09.03.02).

(2002 b): “¿Una Escuela del Siglo XIX en el Siglo XXI?

Redefiniendo las Metas, Formas y Políticas de la Educación en la Era Digital". http://webpages.ull.es/esers/manarea/Documentos/documento9.htm (Cons. 12.03.02).

$-$ (2002 c): "Sociedad de la Información y Analfabetismo Tecnológico: Nuevos Retos Para la Educación de Adultos", http:// webpages.ull.es/esers/manarea/Documentos/documento10.htm (cons. 12.03.02).

- _ (1998): "Una Nueva Educación Para el Nuevo Siglo", Revista NETDIDACTIC@, $\mathrm{n}^{\circ} 1$, octubre.

- __ (1998) "La Educación Para los Medios de Comunicación. Apuntes Para una Política de Integración Curricular", en Revista medios y educación, $\mathrm{n}^{\circ} 7$, junio.

- BERGER, P., y LUCKMAN T., (1979): La construcción social de la realidad. Amorrortu, Buenos Aires.

- CABERO, A. Julio (1997): "Más allá de la planificación en la Educación en Medios de Comunicación", en comunicar, $\mathrm{n}^{\circ}$ 8, 39-48, Universidad de Sevilla.

- CHIRIBOGA, Bolívar (2000): "La Educación Para los Medios", Facultad de Ciencias Humanas y Sociales, Comunicación Social y Antropología Aplicada. Universidad Politécnica Salesiana, Quito, Ecuador.

- ESTEINOU MADRID, Javier. (2000): "Globalización, medios de comunicación y cultura en México a principios del siglo XXI". En Ámbitos n 5, $2^{\circ}$ Semestre (p.p. 7-49).

- GONZÁLEZ VIDEGARAY, Maricarmen (1998): "La historieta como instrumento educativo", en VVAA: Didáctica de los medios de comunicación. SEP, México.

- KAPLÚN, Mario (1997): "La educomunicación; De medio y fines en comunicación”. En Chasqui, junio, no 58. 
- MARTÍNEZ DE TODA Y TERRERO, José (1999): Las seis dimensiones de la educación para los medios. (Metodología de evaluación), Universidad Gregoriana, Italia.

- MARTÍNEZ Z., Irene (2000): “Tres Pilares de la Educación para los Medios”, ILCE (Instituto Latinoamericano de Comunicación Educativa). http:// www.uned.es/ntedu/comunicación-educativa/artirene.htm (cons. 11.04.00).

- MASTERMAN, L. (1993): La enseñanza de los medios de comunicación, Madrid, ediciones de la Torre.

- MINIAN, Judith: "Aplicaciones del uso de la informática y las nuevas tecnologías de la información y la comunicación en el ámbito educativo". http:// maestrasjardineras.com.ar

- OCDE, (1994): Políticas Nacionales de la Ciencia y la Tecnología. México.

- SAPEAS, Enric (1987): Los efectos cognitivos de la comunicación de masas. Ariel Comunicación.

- SHEPHERD, Rick (1997): "Raíces: Origen y desarrollo de los profesores de medios" en Media Literacy Resource Guide, Association for media literacy, Toronto, Canadá

- TYNER, K. (1997): "Conceptos clave de la Educación para los Medios de Comunicación", en APARICI, R. (coord.): La Educación para los Medios de Comunicación. SEP-ILCE México. (pp. 34-39). 